ARTICLE

Received 18 Nov 2015 | Accepted 21 Nov 2016 | Published 13 Dec 2016

\title{
Evaluation of the quality of science, technology and innovation advice available to lawmakers in Nigeria
}

Maruf Sanni ${ }^{1}$, Omolayo Oluwatope ${ }^{1}$, Adedamola Adeyeye ${ }^{1}$ and Abiodun Egbetokun ${ }^{1}$

\begin{abstract}
Access to quality science, technology and innovation (STI) information by lawmakers, as one of the key determinants of the effectiveness of policies in sub-Saharan Africa, has generated much debate. The main objective of this article therefore is to examine the sources of, and access to, STI information available to lawmakers in Nigeria. We also investigate factors associated with the use of STI information from experts and other sources in the policymaking process in Nigeria. Data were collected from lawmakers in both the state and national assemblies across Nigeria. Those selected from the states are those with an active S\&T structure, such as a fully fledged Ministry dedicated to S\&T. The sample was drawn from legislators in S\&T committees and other cognate ministries. Our findings reveal that most lawmakers do not use evidence-based STI information on a regular basis. We also note that the use of expert opinion is one of the main sources of STI information, while academic journals and public opinions are some of the least utilized sources. Some of the major factors that affect the use of information from experts are the law makers' level of education, number of years spent in the committee and duration of period as members of a committee. We recommend regular capacity-building programmes for legislators and their scientific advisers and personal assistants. This article is published as part of a collection on scientific advice to governments.
\end{abstract}

\footnotetext{
${ }^{1}$ National Centre for Technology Management, Ile Ife, Nigeria Correspondence: (e-mail: marufsanni@yahoo.com)
} 


\section{Introduction}

cience, technology and innovation (STI) are the basis upon which a sustainable economy can be developed. This has even become more important as many nations are beginning to move toward knowledge-based economies (Enderby, 2008). Meanwhile, developing countries are often confronted with many challenges, from funding of scientific research, engaging skilled research personnel to communication of the research outputs and specific scientific information for policymaking. Developing countries like Nigeria are often advised to evolve a system that harnesses, develops and utilizes STI to build a large, strong, diversified, sustainable and competitive economy that guarantees a high standard of living and quality of life of the citizens. At the same time, policymakers and other stakeholders must consistently advance policies that link natural resources and topical research agenda to national priorities and facilitate demand driven innovation activities. Unfortunately, the reality on the ground suggests otherwise. In many occasions, STI as an instrument of choice for sustainable economic development is still not being given the desired role within the national agenda. For instance, Nigeria's Gross Expenditure on Research and Development of $0.2 \%$ is one of the smallest in Africa despite the fact that Nigeria is reported to be the largest economy in Africa. Some of the reasons for this have been traced to political instability, policy inconsistencies and lack of capability of the policymaking community (Siyanbola, 2011).

In addition, appropriate dissemination and communication of STI research outputs is an area that is commonly overlooked in the discourse on evidence-based policymaking, especially in developing countries. This is important because evidence suggests that nonuptake of scientific information in policy decisions could be as a result of a failure in communication (Schaal, 2008). It is also important to note that failure in articulately communicating research outcomes has negative consequence for efforts to tackle developmental challenges in many developing countries. In other words, proper utilization and communication of scientific research outputs have strong correlation with the development progress of a country. It is not surprising therefore, that many developing economies have advocated for the use of research evidence in providing solutions to the challenges of poverty and inequality in the society (Mayne and Zapico-Goñi, 2007; Newman et al., 2013; UNDP, 2013). In the same vein, accurate use of scientific evidence in the policymaking process has a tendency to save more lives when it meets the needs of the citizens (WHO, 2004). Therefore, the necessity of relevant evidence, especially in developing countries, is rapidly increasing (Datta and Jones, 2011). In this light, using research outcomes from STI to inform policy in all areas that affect the natural, physical and social systems should be the norm (Holmes and Clark, 2008). Unfortunately, the manifestation of evidence in policy processes is constrained by a number of socio-political and structural factors that result in it not being used to the extent that it should be used (Brownson et al., 2006; Ritter, 2011; Haynes et al., 2012). Much more important are the sources and dissemination of scientific evidence to policy makers in such a way that policy decisions are based on scientific evidence. From the foregoing, it is imperative that nations build capability on how to disseminate evidence and integrate such evidence into policy decisions for sustainable economic development. Some of the factors affecting evidence uptake in the policymaking process are illustrated in Fig. 1. This figure reflects some of the complexities affecting the policymaking process at the research-policy interface.

\section{Policy and law making structures in Nigeria}

Nigeria operates a Presidential System of government with three tiers: the Federal, State and Local Government. There are 36

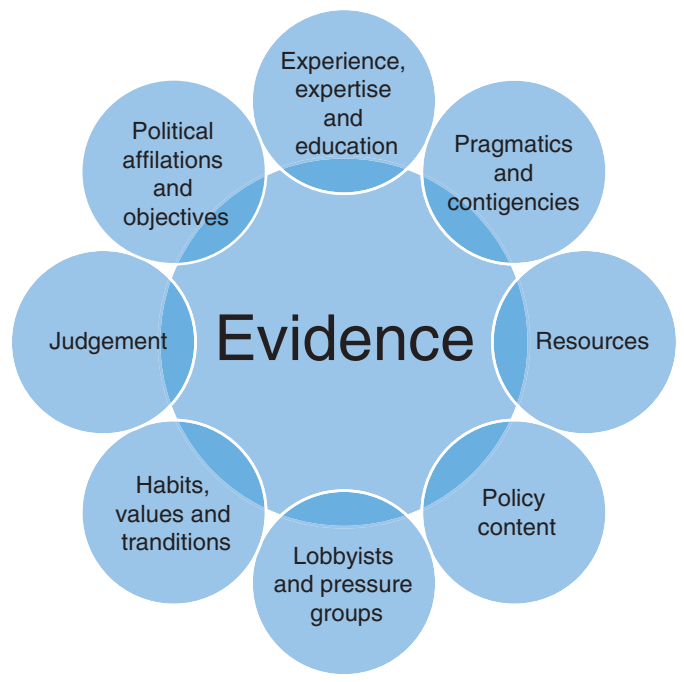

Figure 1 | Factors influencing policymaking.

Source Adapted from Davis (2005); Jones and Walsh (2008).

states, 1 Federal Capital Territory (FCT) and 774 local government areas in Nigeria. The FCT is located centrally in Abuja with the aim of having a national capital where there would no dominance of any of the over 250 ethnic groups in the country (Ignatius and Dakas, 2005). For ease of administration, every state is divided into Local Government Areas. Like many democracies in the world, the country operates three arms of government: Executive, Legislature and Judiciary. While the Executive implements government policies and programmes, the Legislature, aside from formulating the law, serves as a check on the executive branch of government. The judiciary on the other hand, enforces the law. The executive branch of the government is divided into federal ministries that are presided over by the ministers that are chosen by the president. Each ministry would push the agenda of the federal government through their several parastatals.

The country runs a bicameral legislature at the Federal level: the Senate and the House of Representative. The two chambers are also called the National Assembly (NACETEM, 2008).The states however operate a unicameral legislature, the house of Assembly. Within the National Assembly, the House of Representatives is presided over by the Speaker while the Senate President directs the affairs of the Senate. The House of Representatives has 360 members, elected from constituencies in the 36 States. The number of constituencies is allotted based on the population of each State. However, the Senate has 109 members, with three members from each of the 36 states and one from the FCT (NACETEM, 2008). The legislators are elected for a 4-year, unrestricted tenure. In order for STI to play a vital role in national development, there is the need for all the stakeholders to develop a strategy not only to undertake research, particularly in STI, but also to utilize the results in policymaking. Seamless coordination of all the actors such as the policymakers in the executive, lawmakers in the legislature and other support staff is needed to effectively diffuse and articulate the outcome of research in policy and ultimately in development. More importantly, the need for lawmakers to understand the dynamics and importance of STI in national development is crucial to research communication and uptake. While policy makers on the executive side are in many instances equipped with the needed capabilities to formulate and implement policies, lawmakers, who are mostly politicians, lack the requisite knowledge to effectively pass laws on issues related to STI. In addition, their busy schedules make it more difficult to devote time 
to developing the capabilities. They therefore depend on external sources of knowledge for information, which in many instances are inadequate, inappropriate, or obsolete. This article therefore seeks to examine the capabilities of lawmakers and the supporting structure in Nigeria with respect to the use of expert opinion as a source of information on STI-related matters. We focus on lawmakers because there seems to be a dearth of information and empirical studies of the utilization of empirical evidence among lawmakers in developing countries. In addition, our analysis of the use of expert opinion instead of other "hard" knowledge sources such as academic journals is because of the high dependence on this source of information by lawmakers in Nigeria.

\section{Legislative staff capacity in policymaking}

More often than not, legislators are running against time and are frequently bombarded with many sources of information such as policy briefs, expert opinion, newsletters, public opinion polls, assembly motions and resolutions, conference proceedings and scientific journals. As a result of this, they are likely to make hasty policy decisions by opting for the "evidence" most suitable to their political objectives (Edwards, 1999). It goes without saying therefore that there should be deliberate efforts to strengthen the capabilities of the support staff within the policy community such as the legislative staff, personal assistants, political experts, consultants that are responsible for disseminating and synthesizing scientific information for the lawmakers during policymaking process. This in line with the people-focused theory of change of Stewart (2015), which noted that the use of evidence in policymaking should involve "pull" activities with more exchange of ideas between the producers and users of scientific evidence. Buttressing this, Clark and Juma (2002) noted that the capacity of communication channel between experts and policy makers in many developing countries is not only inadequate but also full of undue contraction of scientific information. Other issues affecting uptake of scientific evidence in policymaking process is that of perception that the relationship between research and policymaking is a linear process. As such many believe that effective research outputs could easily be implemented into policy (Young and Court, 2004). In actual fact, policymaking is a complex process of various competing factors in the utilization of evidence (Davies, 2005) (see Fig. 1). In addition, quite a number of barriers have also prevented the use of scientific evidence in policymaking process. Some of these barriers are found at both individual and organizational levels as well as at the point of communication (Clar et al., 2011). Similarly, the S\&T governance and its historical antecedent is another important factor that could affect the use of evidence in policy process. In view of this, it is vital that effective use of scientific evidence in policymaking therefore necessitates strengthening the communication channels as well as understanding and engagement with the competing factors in policymaking process.

\section{Legislative communication channels and policymaking process}

To simplify the complexities in policymaking process, legislators depend greatly on information from their staff and other sources such as consultants, policy researchers, and political experts. Studies have also revealed that a lot of legislators have more confidence in information coming from their staff more than those that come from any other sources. Of importance to this study are the roles and quality of scientific evidence from the permanent or ad hoc legislative staff appointed by the legislators. These categories of staff are usually referred to using different appellations such as personal assistants, special advisers, political experts, consultants and so on. Their roles are usually ambiguous.
These include consulting with party members on matters concerning government policies, liaising with the media, offering expert opinion to the legislator on topical issues that affects the citizens, participating in party meetings and interacting with party members, helping with the drafting of policies and engaging in policy reviews with the purpose of advancing interest of the legislator and the objectives of the party. A quick assessment of these job functions gives the impression that these categories of people do not only occupy a privileged position but also play an important role in policymaking process. However, it will amount to misinformation if this group of people is categorized or perceived as homogenous. For instance, when they are categorized based on their job functions, we may have disinterested experts, partisan experts, or "non-expert" political advisers (Eichbaum and Shaw, 2010). In broader term, they could be categorized into two: partisan and non-partisan staff. They could also be permanent or ad hoc.

The non-partisan staff members are usually civil servants who are often not influenced by political interests. They are found in places such as the secretariats of the committees, National Institute for Legislative Studies, as well as National Assembly Library. In contrast, the partisan members of staff are those appointed by their party caucuses or a particular legislator. These set of people serve the interest of their party as well as that of the legislator who employed them. Their job functions include desktop research on policy issues, interacting with the media, giving legal opinion on policy issues, bill drafting, policy review, intermediary role between consultants and the legislators and providing expert opinion on complex policy issues. They are usually ad hoc staff whose tenure will not be longer than that of the legislators. This category of staff form the bulk of the legislative ad hoc staff employed by the lawmakers in SubSaharan Africa (Jones and Tembo, 2008; Datta and Jones, 2011) and their role in the policymaking process is the focus of this article. This article addresses the deficit in literature pertaining to the role of partisan legislative staff in the policymaking process in Nigeria. The objective of this study therefore is to examine the quality of scientific evidence provided by this group of legislative staff to the legislators. We hypothesize that applications of scientific evidence from the partisan legislative staff would be affected by value, experience and philosophical understandings and level of education of the lawmakers as well as their political leanings. As such there are tendencies that there would be lack of openness in the scientific advisory service that are provided to the legislators. At the same time, there could be absence of a consistent and objective approach to policy research.

\section{Research methodology}

Data. The data for this article was gathered from a project that assessed the literacy level of policy makers in the utilization of scientific information in policy-making process in Nigeria (NACETEM, 2008). The project was funded by the Swedish International Development Agency and was facilitated by the New Partnership for African Development Planning and Coordinating Agency. Data was collected from respondents in the National Assembly and from six states, each one purposively selected from the six geopolitical zones of the country. These are states with an active S\&T structure such as a full-fledged Ministry dedicated to S\&T. The selection in each of the geopolitical zones was carried out to enhance national spread and representativeness of the data. The six states selected are Lagos (South West), Enugu (South East), Bayelsa (South South), Kano (North West), Niger (North Central) and Bauchi (North East). However, because of security challenges in the North East, the zone was excluded from the survey. In all, a total of 50 lawmakers were selected. 
The respondents in this study include legislators in committees of the National and State Assemblies which have oversight responsibilities on the core S\&T-related activities and other cognate ministries. These committees include Science and Technology, Agriculture, Health, Education and Trade and Investment. Since Nigeria operates a bi-cameral legislature at the Federal level, members of both the Senate and House of Representatives were sampled. Other respondents sampled include the Clerk of each Committee, researchers at the National Institute for Legislative Studies and the Librarian at the National Assembly Library. Factors such as socio-demographics of the lawmakers, awareness, access and utilization of key scientific information relevant to their performance as a member of committees in the national assemblies were investigated in the administered questionnaire. We also examined policy makers' sources of knowledge, level of interest and obstacles to accessing scientific information. We use information from legislative staff, personal assistants, political experts, consultants and partisan legislative staff as proxy for expert opinions. To examine our hypothesis that application of scientific evidence from the partisan legislative staff would be associated with value, experience, philosophical understanding, level of education of the lawmakers as well as their political leanings, we carried out a probit regression. Use of information from expert opinion was coded as 1 , while the use of other sources was coded as 0 .

\section{Analysis of results and discussions}

Information on socio-demographic distribution of legislators in Nigeria is contained in Table 1 . Our sample reveals a maledominated chamber with female legislators accounting for only $12 \%$ of our sample. Our sample reflects the gender state of legislators in Nigeria. For example at the National Assembly, about $6.4 \%$ of the entire 469 members are female (NBS, 2011). The gender imbalance in membership of the legislature is not peculiar to Nigeria but common in most African countries. For instance, about $8 \%$ of legislators in Kenya are female (Barkan and Matiangi, 2013). There are improvements in some countries because of special constitutional provisions made for women representation (Uganda) or proportional representation (South

\section{Table 1 | Socio-demographics of the policy makers}

\begin{tabular}{lr} 
Socio-demographic characteristics & $\%$ \\
\hline Sex $(n=50)$ & \\
Male & 88.0 \\
Female & 12.0 \\
Age $(n=50)$ & \\
Below 40 & 14.0 \\
$40-49$ & 54.0 \\
$50-59$ & 32.0 \\
Highest educational qualification $(n=49)$ & \\
SSCE & 2.0 \\
ND & 36.7 \\
Bachelor/HND & 22.4 \\
PGD & 20.4 \\
Master & 16.3 \\
Doctorate & 2.0 \\
Field of Study $(n=48)$ & \\
Science & 8.3 \\
Engineering & 2.1 \\
Humanities & 22.9 \\
Social sciences & 56.3 \\
Agriculture & 2.1 \\
Medical sciences & 2.1 \\
Education & 2.3
\end{tabular}

Africa, Mozambique) (Barkan and Matiangi, 2013). This observation is most likely to have some policy implications with impact on the quality and direction of debates especially relating to issues of women not only in Nigeria but also in Africa.

The age distribution of the legislators shows that majority (54\%) belong to the age group 40-49 years, while those between ages $50-59$ years constitute $32 \%$ and $14 \%$ fall below the age 40 (see Table 1). This is similar to situation in other African countries. In Kenya for example, though the average age of lawmakers in the tenth parliament was about 50 years, the highest proportion of $37.1 \%$ is in the age range of 40 to 49 (Barkan and Matiangi, 2013). The higher middle age range in Nigeria may be attributed to the constitutional requirement for becoming a legislator in Nigeria which requires a person aspiring to become a Senator to have attained an age of 35 years, while that of the House of Representatives is a minimum of 30 years (FRN, 1999). Presently, the youngest age of the member of eighth Senate is 40years while the oldest is 74years.In advanced economies, such as the United States, the average age of legislators is higher. For example in the 112th Congress of the United States, the average age of Members of the House was 57 years while that of the Senate was 62 years. The higher average age in the United States, as in the case with most established democracies may be attributed to low rate of turnover among legislators. In Nigeria, there is a high turnover among legislators, which has been described as one of the highest in the world (NASS, 2012).

The educational qualification of legislators, both at the National and State assemblies are of paramount importance to the formulation of policies in the country as it could help in mainstreaming sustainable STI strategies into the domain of public policies. Analysis in Table 1 reveals that over $50 \%$ of the legislators have at least a university degree or its equivalent. While about $17 \%$ holds a Master and just $2 \%$ has a doctorate degree. This shows that the legislators possess the required capability to undertake their legislative activities. Given the significant number of bachelor's and postgraduate degrees holders among the committee members, this portrays legislators with the capacity to assess, understand, analyse and utilize scientific information and be able to contribute meaningfully to debates and the policy formulation process.

The analysis also displays the field of study (area of specialization) of the legislators. Our result shows that majority of them (56\%) had their educational background in the social sciences. Slightly one-fourth of them were from the humanities field of study and one-tenth from the sciences. Respondents from the medical sciences, agricultural sciences and engineering field of study had few representations; less than one-tenth of the whole. This was observed in both the national and state assemblies when the analysis was disaggregated.

Experience of lawmakers. The experience of lawmakers is explained in terms of their years in the relevant legislative houses as well as in their respective committees (Table 2). While the majority of the lawmakers have spent between 4 and 8 years in the legislative Houses, only approximately $16 \%$ have spent more than 4 years in a particular S\&T-related committee. These results show a high turnover in both membership of the legislature and the committees. This could hinder capacity building and knowledge sharing in specific areas of S\&T.

Knowledge of key relevant scientific information. To assess the knowledge of lawmakers in Nigeria with regards to science, technology and innovation, some questions were asked. These include questions on knowledge of specific scientific indicators such as patent, R\&D intensity. The result as presented in Table 3 


\begin{tabular}{|lc}
\hline Table 2 | Experience of legislators & \\
& $\%$ \\
\hline Years spent in Committee $(n=45)$ & \\
$1-4$ & 83.5 \\
$5-9$ & 12.4 \\
$>10$ & 4.1 \\
Years spent in state/National assembly $(n=48)$ & 14.6 \\
Less than 4 years & 43.8 \\
$4-8$ years & 12.5 \\
9-12 years & 29.2 \\
More than 12 years &
\end{tabular}

shows that most of the legislators do not understand these terms despite their claim to the affirmative. For example, only $21 \%$ of the respondents understood the meaning of R\&D intensity. Similarly, a large majority, about $65 \%$, had no idea of the recommendation of African Union on R\&D Intensity (percentage of GDP dedicated to R\&D). However, two-thirds of the legislators understood the meaning of patent.

\section{Sources of scientific information consulted for policy formulation}

Lawmakers in both the national and state assemblies consult many sources of scientific information in their lawmaking activities. Table 4 illustrates many of these sources. Our analysis reveals that expert opinion, internet, and workshop/seminars/ conferences are the most important sources of information for legislators. However, formal sources such as learned journals were not important sources of information for legislators.

Obstacles to accessing scientific information. Utilization of scientific information such as STI indicators in law-making process is predicated on several factors, which can be classified broadly into the nature, medium of information and the capacity and lifestyle of the user. The major obstacles to legislators' utilization of scientific information are listed in Table 5. The biggest obstacle is the insufficiency of information on S\&T challenges $(50.0 \%)$. This may come in the form of medium and nature of producing these indicators. This is followed by inaccessibility of information (41.5\%); obsoleteness of information $(37.8 \%)$ and uncertainty of the integrity of the source of information (35.6\%). One would however have expected the busy lifestyle of the legislators to constitute a major obstacle. However, this was not so. This suggests that despite their busy schedules, most legislators would still find a way to utilize these indicators if they are accessible, up-to-date, sufficient and friendly. Technicality of information was also not an obstacle to scientific information utilization. This suggests that the first concern of legislators is inaccessibility to relevant key scientific information.

Factors influencing the utilization of scientific information from experts. Nigeria is bedeviled with lack of quality and current data especially related to STI. Most countries lack institutions to produce these and where they exist, lack the capability. The few datasets found in international databases are in most cases inaccurate and obsolete, and hence do not represent the facts on the ground in most developing countries especially, sub-Sahara Africa. We work with the assumption that majority of the legislative staff employed as political experts, consultants or personal assistants by many law makers in developing countries, especially Nigeria are partisan. As such, utilization of scientific evidence from the partisan legislative staff would most likely be affected by value, experience, philosophical understandings and level of
Table 3 | Knowledge of relevant scientific information by lawmakers

\begin{tabular}{lc} 
& $\%$ \\
\hline Awareness of relevant scientific information ( $n=46)$ & 71.7 \\
Knowledge on STI indicators & \\
$\%$ Benchmark of GDP investment on R\&D for African countries $(n=50)$ \\
1 & 10.0 \\
3 & 5.0 \\
5 & 10.0 \\
10 & 10.0 \\
No idea & 65.0 \\
Implication of Nigeria's R\&D intensity of $0.2(n=39)$ & \\
It means that the amount of GDP devoted to R\&D in Nigeria & 20.5 \\
is O.2\% & \\
It shows that with minimum effort Nigeria can become global & 20.5 \\
R\&D player by year 2020 & \\
It shows that the level of R\&D activities in Nigeria is low & 59.0 \\
PATENT ( $n=48$ ) & 8.3 \\
Number of patients admitted in the hospital & 66.7 \\
Inventions protected by law & 10.4 \\
R\&D outcomes lacking applicability & 14.6 \\
R\&D product/process that leads to wealth creation when \\
exploited
\end{tabular}

\section{Table 4 | Sources of information consulted for policy formulation}

Sources of information consulted for policy formulation $(n=163)$ * $\%$

Expert opinion

Internet

Workshop/seminars/conferences

17.2

Newsletter

Policy brief

Learned Journals/articles

Public opinion polls

Assembly motion/resolutions

${ }^{\star}$ Multiple response item

education of the lawmakers as well as their political leanings. On the basis of this assumption, we investigated factors that might impact on the use of scientific information from such legislative staff. We investigated this using a probit regression model.

Some of the variables used in this analysis include age of law makers, educational level, field of study, years spent in state/ national assemblies, awareness of key relevant scientific information and number of years spent as a member of committee. The field of study and educational level were used as variable to measure the impact of education, while number of years spent as legislators and in legislative committees were used as proxy for legislative experience. Expert opinion was used as the dependent variable and coded as " 1 " if a particular law maker uses the source and "0" if otherwise. This source was used as proxy for scientific information coming from legislative staff such as personal assistants, political experts, partisan legislative staff or ad hoc legislative staff.

From the result of the analysis (Table 6), it was revealed that variables measuring factors such as the educational qualification of the legislator, awareness of indicators among the legislator as well as experience of the legislator as captured by the number of years spent in the state/national assembly were found to be significantly associated with the sources of STI information. The 


\section{Table 5 | Obstacles to accessing scientific information}

\begin{tabular}{|c|c|c|c|}
\hline Obstacles to accessing scientific informaiton & Never an obstacle (\%) & Sometimes an obstacle (\%) & Usually an obstacle (\%) \\
\hline Insufficient information on S\&T challenges & 20.4 & 29.5 & 50.0 \\
\hline Inaccessibility of information & 24.4 & 34.1 & 41.5 \\
\hline Obsoleteness of information & 29.7 & 32.4 & 37.8 \\
\hline Technicality of the source of information & 41.0 & 28.2 & 30.7 \\
\hline Lack of clarity of information & 34.2 & 37.1 & 28.6 \\
\hline Scanty information & 24.3 & 48.6 & 27.0 \\
\hline
\end{tabular}

Table 6 | Factors influencing the application of scientific information from experts

\begin{tabular}{|c|c|c|c|c|c|}
\hline Educational level & 0.57 & 0.25 & 0.02 & 0.074 & 1.065 \\
\hline Years spent in State/National Assembly & -0.68 & 0.28 & 0.02 & -1.229 & 0.128 \\
\hline Awareness of indicators & 1.07 & 0.51 & 0.04 & 0.071 & 2.075 \\
\hline Duration of years spent in committee & 0.03 & 0.50 & 0.95 & -0.948 & 1.016 \\
\hline Constant & 1.07 & 1.18 & 0.36 & -1.229 & 3.379 \\
\hline
\end{tabular}

implication of this analysis is that in trying to sieve the truth from scientific information coming from the legislative staff or consultants; factors such as education level, experience of the legislator as well as adequate knowledge of the relevant key scientific information are critical.

\section{Conclusion and recommendations}

Adequate access to relevant scientific information by law makers for policymaking can help a country leverage on the benefits of knowledge-based economy as well as globalization. This is even more important given the fact that the interaction between knowledge and its application can yield different outputs for societies at different levels of development with a lot of implications on policy formulation and implementation. Meanwhile, scientific evidence is just one of many factors from array of other complex, competing factors that influence the application of scientific evidence in policymaking process. It is important therefore that policy makers pay attention to the communication channels as well as understanding the impact of scientific knowledge in policymaking process in Nigeria.

This paper examined access and utilization of scientific information in lawmaking process among legislators in Nigeria. The law makers came from different background and with diverse level of experience. For diversity of opinions and knowledge on evidence-based policymaking, they were selected from S\&T and other cognate committees from both the national and state assemblies. In addition to S\&T, other committees selected include trade and industrial, agriculture, health and education. We designed and administered structured questionnaires to elicit information from legislators on the awareness and use of scientific information in policymaking process in Nigeria. We explored the less-studied role of partisan legislative staff, political expert consultant, personal assistant and special advisers, involved in conducting desktop research on policy issues, giving legal opinion on policy issues, bill drafting, intermediary role between the public and the legislators and providing expert opinion on complex policy issues. We work with the assumption that the majority of the legislative staff employed as political experts, consultants or personal assistant by many law makers in the developing countries, most especially in Nigeria, are partisan. As such, utilization of scientific evidence from these staff would most likely be affected by value, experience, philosophical understandings and level of education of the lawmakers, as well as their political leanings. On the basis of this assumption, we investigated factors that might impact the use of scientific information from such staff.

The analysis of the socio-demographics of law makers revealed that both the national and state assemblies are male-dominated. In terms of age, majority of the legislators are adult with age ranging between 40 and 49 years. We also found out that most of the lawmakers are graduates with most of them having background in social sciences. Further analysis showed that while majority of the lawmakers have spent between 4 and 8 years in the legislative houses, only about $16 \%$ spent more than four years in a particular S\&T-related committee. This shows a high level of turnover in membership of the legislature. Also, while majority of the law makers claimed to be aware of the key relevant scientific information applicable to their legislative functions in S\&T, our results show otherwise. However, when it comes to the formulation of policies, most of the law makers utilized expert opinion as their major source of scientific information. This result confirms our earlier assumption that most legislators depend on the advice from political experts, consultants, partisan legislative staff, personal assistants and political advisers (categorized here as expert opinion) for scientific information for lawmaking. On the obstacles to accessing scientific information, insufficient information on S\&T challenges, inaccessibility of information and uncertainty of the integrity of the source of information were the major inhibitors. The analysis of the factors that impact the 
use of scientific information from the experts reveals that number of years spent in the legislative houses, level of education of the lawmakers as well as years of experience as committee members are important. These results have a lot of implications for lawmaking in Nigeria.

On the basis of the empirical findings emerging from our study, we offer the following propositions on how to entrench effective access to and utilization of scientific information for lawmaking in Nigeria:

- Despite the fact that majority of the legislators claimed to be aware of the relevant key scientific information, their utilization of these scientific knowledge is very low. This necessitates the need to build the capacity of the law makers on how to access and utilize relevant scientific information for policymaking in Nigeria;

- Since one of the major sources of scientific information for the policy makers is from partisan experts, it becomes necessary therefore that the capacity of both the lawmakers and their political advisers, including personal assistants and other legislative staff should be enhanced;

- In terms of the challenges to access scientific information and integrity of sources of information, lawmakers may want to engage the expertise of non-partisan and reputable consultants in accessing relevant scientific information.

- Conscious efforts should be made in the electoral process to elect educated citizens as legislators in Nigeria while those with a lot of experience should mentor young ones in the art of lawmaking, especially in relating to S\&T issues.

\section{References}

Barkan D and Matiangi F (2013) Kenya's tortuous path to successful legislative development. Reprinted from J D Barkan (ed), Legislative Power in Emerging African Democracies (2009) 33-72, 9.

Brownson RC, Royer C, Ewing R and Mcbride TD (2006) Researchers and policymakers: Travelers in parallel universes. American Journal of Preventive Medicine; 30 (2): 164-172.

Clar C, Campbell S, Lisa D and Wendy G (2011) What are the Effects of Interventions to Improve the Uptake of Evidence from Health Research Into Policy in Low and Middle-Income Countries?. DFID: London.

Clark W and Juma C (2002) Mobilizing Science and Technology for Sustainable Development. Forum on Science and Technology for Sustainability. (http:// www.ksg.harvard.edu/sustsci/ists/docs/ists_cfia_rpt_final.pdf), accessed 13 June 2015

Datta A and Jones N (2011) Linkages between researchers and legislators in developing countries A scoping study. Overseas Development Institute, Working Paper 332. London.

Davies P (2005) Presentation: Impact to Insight Series. ODI: London.

Edwards A (1999) Scientificexpertise and policy-making: the intermediary role of the public sphere. Science and Public Policy; 26 (3): 163-170.

Eichbaum C and Shaw R (eds.) (2010) Partisan Appointees and Public Servants: An International Analysis of the Role of the Political Adviser. Edward Elgar Publishing, Cheltenham, UK.

Enderby J (2008) Knowledge, validation, and transfer: science, communication, and economic development In: Schweitzer, (ed.) Science and Technology and the Future Development of Societies: International Workshop Proceedings. National Academies Press. Washington DC.

Federal Ministry of Information and National Orientation. (1999) Constitution of the Federal Republic of Nigeria. Federal Ministry of Information and National Orientation, Abuja, Nigeria.

Haynes AS et al (2012) Identifying trustworthy experts: How do policymakers find and assess public health researchers worth consulting or collaborating with? PLOS ONE; 7 (3): e32665.
Holmes J and Clark R (2008) Enhancing the use of science in environmental policymaking and regulation. Environmental Science and Policy; 11 (8): 702-711.

Ignatius Akaayar Ayua and Dakas Dakas C.J. (2005) Federal republic of Nigeria, constitutional origins, structure and change In: Federal Countries (ed.) Kincaid, J and Alan Tarr, G. Montreal and Kingston: McGill-Queen's University Press, (2005), 241-248.

Jones $\mathrm{N}$ and Tembo F (2008) "Promoting good governance through civil societylegislator linkages: Opportunities and challenges for policy engagement in developing country contexts." International Third Sector Research Conference. Barcelona, 9-12 July.

Jones N and Walsh C (2008) Policy briefs as a communication tool for development research.Overseas Development Institute Background Note, May 2008. London.

Mayne J and Zapico-Goñi E (eds) (2007) Monitoring Performance in the Public Sector: Future Directions from International Experience. Transaction Publishers: New Jersey, USA.

NACETEM (National Centre for Technology Management). (2008) Nigeria's Science, Technology and Innovation Indicators: Report of 2006/07R\&D Survey (1st Edition)-NACETEM Policy Research Project Report, Ile Ife, Nigeria.

NASS (National Assembly). (2012) Review of the Institutional Structures and Processes Related to the MDGs in the Parliament of Nigeria, http://www.ipu. org/splz-e/unga13/nigeria.pdf, accessed 5 September 2015.

NBS. (2011) Women in a transforming Nigeria. Gender Statistics; 2 (4).

Newman K, Capillo A, Famurewa A, Nath C and Siyanbola W (2013) What is the evidence on evidence informed policymaking? Lessons from the International Conference on Evidence Informed Policymaking, Oxford: International Network for the Availability of Scientific Publications (INASP).

Ritter A (2011) The role of research evidence in drug policy development in Australia. Croatian Political Science Review (PolitickaMisao); 48 (5): 141-156.

Schaal B (2008) The role of communications and scientific thinking. In: Schweitzer, ed. Science and Technology and the Future Development of Societies: International Workshop Proceedings. National Academies Press. Washington DC

Siyanbola WO (2011) STI governance in Nigeria: The role of parliament. A paper presented at the launching of African Inter-Parliamentary Forum on Science, Technology and Innovation (AIP-STI) on 2nd of May, 2011 at Addis-Ababa, Ethiopia.

Stewart R (2015) A theory of change for capacity building for the use of research evidence by decision makers in southern Africa. Evidence \& Policy: A Journal of Research, Debate and Practice; 11 (4): 547-557.

UNDP (United Nations Development Program). (2013) Equity, Inequality, and Human Development in a Post-2015 Framework. UNDP: New York.

WHO (World Health Organisation). (2004) World Report on Knowledge for Better Health: Strengthening Health Systems. WHO:Geneva, Switzerland. (http://www.who.int/rpc/meetings/world_report_on_knowledge_for_better_ health.pdf).

Young J and Court J (2004) Bridging Research and Policy in International Development: An Analytical and Practical Framework. RAPID Briefing Paper 1, London: ODI.

\section{Data availability}

The datasets generated during and/or analysed during the current study are not publicly available due to the agency's policy. However, these are available from the corresponding author on reasonable request.

\section{Additional information}

Competing interests: The Authors declare no competing financial interests.

Reprints and permission information is available at http://www.palgrave-journals.com/ pal/authors/rights_and_permissions.html

How to cite this article: Sanni M et al. (2016) Evaluation of the quality of science, technology and innovation advice available to lawmakers in Nigeria. Palgrave Communications. 2:16095 doi: 10.1057/palcomms.2016.95.

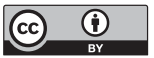

This work is licensed under a Creative Commons Attribution 4.0 International License. The images or other third party material in this article are included in the article's Creative Commons license, unless indicated otherwise in the credit line; if the material is not included under the Creative Commons license, users will need to obtain permission from the license holder to reproduce the material. To view a copy of this license, visit http://creativecommons.org/licenses/by/4.0/ 